\title{
Beyond political affiliation: an examination of the relationships between social factors and perceptions of and responses to COVID-19
}

\author{
Berkeley Franz ${ }^{1}\left[\right.$ [ $\cdot$ Lindsay Y. Dhanani ${ }^{2}$
}

Received: 8 August 2020 / Accepted: 10 April 2021 / Published online: 20 April 2021

(C) The Author(s), under exclusive licence to Springer Science+Business Media, LLC, part of Springer Nature 2021

\begin{abstract}
A significant challenge in the United States' response to COVID-19 continues to be wide variation in the extent to which individuals believe the virus is a credible health threat and are willing to undertake measures to protect personal and public health. In this study, data were collected from a national sample of 1141 participants from the United States to examine how beliefs and behavioral responses to COVID-19 have been shaped by sociopolitical characteristics. The relationships between social predictors; perceived severity, knowledge, and fear of the virus; and health behaviors were tested using path analysis. Social characteristics significantly predicted perceived severity, knowledge, and fear, as well as health behaviors, even after controlling for an objective indicator of the risk of contracting the virus. Our findings suggest that perceptions and knowledge of the virus, especially believing that the virus poses a serious threat to one's individual health, are important determinants of behavior, but also that perceptions and knowledge are strongly driven by social and cultural factors above and beyond political affiliation.
\end{abstract}

Keywords COVID-19 . Health behaviors $\cdot$ Social factors $\cdot$ Risk $\cdot$ Health beliefs $\cdot$ Politics

SARS-CoV-2 emerged as a novel virus in late 2019 and has since caused a large and sustained infectious disease

Berkeley Franz

franzb@ohio.edu

1 Department of Social Medicine, Heritage College of Osteopathic Medicine, Ohio University, Grosvenor 311, Athens, OH 45701, USA

2 Department of Psychology, Ohio University, 22 Richland Avenue, Athens, OH 45701, USA outbreak, known as the COVID-19 pandemic, with documented transmission in nearly every country (Johns Hopkins University, 2020). Although an exact mortality rate was difficult to ascertain in the early months of the pandemic, scientists now estimate that the case mortality rate is approximately $2 \%$. This rate has decreased as more effective treatments have become available, but remains considerably higher than even the most lethal variants of influenza (Faust \& Del Rio, 2020; Johns Hopkins Coronavirus Resource Center, 2020). In the lead up to a widespread vaccination campaign, the best approach to stemming transmission of the virus has been to implement existing public health measures that provide a broad array of protections, such as testing, contact tracing, social distancing, and taking recommended personal hygiene measures (CDC, 2020a, 2020b; Pradhan et al., 2020; Zhang et al., 2020).

Although medications to lessen disease severity and length are now widely available, public health measures remain critical in the United States where cases have strained the health care system and produced shortages of personal protective equipment, ventilators, and trained health care professionals (Gondi et al., 2020; Supady et al., 2021). The success of efforts to encourage compliance with public health recommendations in the U.S, however, has been limited by the spread of misinformation about the virus and variation in the extent to which individuals believe the virus is a credible health threat and thus warrants a need to undertake measures to protect personal and public health (Calvillo et al., 2020; Gollwitzer et al., 2020; Milosh et al., 2020; Pew Research Center, 2020). The aim of this paper, accordingly, is to explore key social factors that correlate with one's willingness to adhere to public health guidance to stem transmission of COVID-19, particularly at the beginning of the COVID-19 pandemic. 


\section{Understanding correlates of perceptions of and behavioral responses to COVID-19}

Several influential models were developed in the last century to explain why and under what conditions individuals are willing to engage in health-protective behaviors such as receiving preventive care and vaccinations (Anderson \& Bartkus, 1973; Langlie, 1977; Rosenstock, 1974). The Health Belief Model is perhaps the most well-known of these models and has been applied to help understand behaviors related to smoking cessation, medication compliance, condom use, and other preventive health behaviors (Carpenter, 2010; Janz \& Becker, 1984). Created by social psychologists in the 1950s, this model has been applied in several disciplines including public health promotion, health communication, and epidemiology (Carpenter, 2010).

The model focuses on four key health beliefs that shape health protective behaviors: (1) perception of risk; (2) perceptions of disease severity; (3) perceptions of the benefit of engaging in health behaviors, including knowledge of how behaviors protect health; and (4) perceptions of barriers to adopting health behaviors. Although the model has offered key insights into the specific beliefs and related barriers that determine critical health behaviors, one major critique of the model that scholars have endeavored to overcome is the lack of focus on social, cultural, and political factors that shape beliefs and behavior (Bish et al., 2011; Langlie, 1977). We argue this is particularly important in understanding behaviors related to COVID-19 in the U.S. because there has been considerable public debate surrounding whether COVID-19 represents a legitimate threat necessitating a broad public health response. Although misinformation related to COVID-19 is not unique to the U.S. setting (Roozenbeek et al., 2020), responses to COVID-19 appear to be strongly shaped by political and social identities (Calvillo et al., 2020; Gollwitzer et al., 2020; Milosh et al., 2020; Pew Research Center, 2020). However, empirical evidence has primarily focused on political affiliation and evidence is needed to investigate the additional sociopolitical factors that may reduce the likelihood of taking critical protective measures to mitigate COVID-19.

Social scientists have expanded the literature on how illnesses are interpreted, emphasizing the role of social factors in the construction of perceived severity and other health beliefs. In particular, the notion of "contested illnesses" underscores the dynamic nature of whether illnesses are believed to be real, dangerous, or worthy of attention (Con$\mathrm{rad} \&$ Barker, 2010). In many ways, COVID-19 is also a contested illness in that widespread disagreement exists as to its authenticity, severity, and the threat it poses to public health (Barrios \& Hochberg, 2020; de Bruin and Bennett, 2020). To date, however, little empirical evidence has been available to test the influence of social factors on beliefs that COVID-19 is a serious disease or decisions to adopt health protective behaviors such as hand washing and social distancing which may help stem transmission. Further, the initial evidence that has examined predictors of beliefs and behaviors related to COVID-19 has focused primarily on demographic characteristics (e.g., Alsan et al., 2020) and we build on this work to explore differences in enduring beliefs and attitudes that may shape responses to COVID-19.

The available literature on other infectious diseases such as influenza may provide insight on how such social factors shape beliefs that COVID-19 is a serious disease. For example, documented factors in vaccine hesitation include distrust in health information received (Velan et al., 2011), media usage and the receipt of misinformation (Bish et al., 2011), health literacy (Castro-Sánchez et al., 2016), and political ideology (Baumgaertner et al., 2018; Hornsey, 2020). Evidence from early national polls suggests that responses to COVID-19 are similarly affected by social and contextual factors. For example, there are sharp divides in perception of risk between political parties (Medina \& Gebeloff, 2020), with republicans and others adopting conservative ideology downplaying their own vulnerability to the virus (Calvillo et al., 2020) and engaging less in social distancing as measured by overall movements and visits to non-essential businesses (Gollwitzer et al., 2020). Evidence also suggests that interpretations of COVID-19 have also been influenced by religion (Porterfield, 2020). Further, due to rhetoric in the U.S. that has continually emphasized the foreign origin of the virus, xenophobic beliefs and fears of foreigners may also be entwined with beliefs related to COVID-19 (Cheng, 2020; Taylor, 2020; White, 2020).

Thus, integrating previous research on the health belief model, contested illnesses, and the role of social characteristics in shaping health responses, the goal of this paper is to test the extent to which social factors shape perceptions of and responses to COVID-19. Our model proposes that social factors are related to perceptions of severity, fear, and knowledge of COVID-19, which subsequently shape health protective behaviors. We focus on severity because this has been advanced as a key belief in the health belief model. Further, we expand on the traditional health belief model to also include knowledge about COVID-19 given the literature that has demonstrated that access to knowledge and exposure to misinformation can be critical barriers to protective health responses (Bish et al., 2011; Castro-Sánchez et al., 2016; Velan et al., 2011). Finally, we include fear because models have also emphasized the role of fear in motivating health behaviors (e.g., Protective Motivational Theory; Rogers \& Prentice-Dunn, 1997) as well as the benefit of incorporating fear into the health belief model (Champion et al., 2005; Rogers \& Prentice-Dunn, 1997). Further, the current study focuses on perceived severity, fear, and knowledge early on in the COVID-19 pandemic, a formative time when limited 
information was available and Americans were asked to follow public health guidance related to hygiene and social distancing.

This paper contributes to the existing literature in two key ways. First, we test the influence of social factors on perceptions of risk related to COVID-19. In doing so, we address prior calls to integrate sociopolitical characteristics into examinations of health responses and behaviors and provide insight into the cultural influences that affect pivotal public health beliefs about COVID-19. Second, we assess the impact of both social factors and perception of risk on the adoption of COVID-19 protective behaviors such as handwashing and social distancing. We also measure decisions to purchase extra supplies which may help individuals comply with stay at home advisories. Understanding what predicts these responses is of critical practical importance because preventative measures are necessary for reducing the scope and duration of the COVID-19 pandemic.

\section{Method}

\section{Participants}

Data were collected from a national sample of 1,141 participants from the United States who were recruited to complete a study on their attitudes and beliefs about the unfolding coronavirus pandemic. Data were collected in the second week of March 2020. During this time, the number of cases of COVID-19 in the United States was starting to markedly increase and health organizations were beginning to recommend behavioral modifications. Participants were recruited through Qualtrics panels, which is a data collection service that recruits participants online via professional panel survey marketing firms. This sampling procedure was adopted because it allowed us to recruit a representative and geographically diverse sample from across the United States. The study was approved by the institutional review board at [name redacted] and all participants provided informed consent prior to completing the survey.

Of our 1,141 participants, $52.1 \%$ identified their gender as male, $46.9 \%$ identified as female, and $0.8 \%$ identified as nonbinary or thirdgender. Participants also reported an average age of 44.66 years old and $72 \%$ of participants identified as religious (as compared to $76.5 \%$ of the U.S. population; Pew Research Center, 2014).. The most commonly reported racial/ethnic identity was White $(74.7 \%)$ followed by Black or African American (13.3\%), Hispanic or Latinx (7.5\%), Asian (5.6\%), American Indian or Alaskan Native $(2.9 \%)$, Native Hawaiian (0.6\%), and Middle Eastern (0.5\%). The racial composition of our sample was similar to that of the United States (White: 76.3\%, Black/African American: 13.4\%, Hispanic or Latinx: 18.5\%, Asian: 5.9\%, American
Indian and Alaskan Native: $1.3 \%$, and Native Hawaiian: $0.2 \%$ ), with the exception of Hispanic/Latinx Americans who were underrepresented in our sample (U.S. Census Bureau, 2019a).

Our sample also varied in educational background, with $22.3 \%$ holding a high school diploma or equivalent, $23.5 \%$ having completed some college but not earning a degree, 13.3\% holding an Associate's degree, 23.7\% holding a Bachelor's degree, $13.6 \%$ holding a Master's degree, and $3.7 \%$ holding either a doctoral or professional degree. We note that our sample had higher levels of educational attainment in comparison to the U.S. population, in which $31.5 \%$ of the population holds a bachelor's degree or higher (as compared to $41.0 \%$ of our sample; U.S. Census Bureau, 2019a, 2019b). Examining political affiliation, $43.5 \%$ of our sample reported they were democrats, $28.9 \%$ identified as independents, and $27.6 \%$ identified as republicans. Finally, the majority of our sample reported their sexual orientation as heterosexual $(87.4 \%)$ with the remaining $12.6 \%$ identifying as gay, lesbian, bisexual, or another sexual identity.

\section{Measures}

The survey was designed to assess participant social characteristics; perceptions and knowledge of COVID-19; and health behaviors. The survey items were developed from previous studies which examined perceptions of and behavioral responses to other public health crises that were adapted to be relevant to the current context (Di Giuseppe et al., 2008; Goodwin et al., 2009; Rubin et al., 2009; Rubin et al., 2010) as well as public health fact sheets assembled to inform the public about COVID-19 (Maragakis, 2020; WHO, 2020). We describe each of our survey measures in more detail below.

To assess social characteristics, we first asked participants about their political affiliation and religious affiliation. Political affiliations included republican, independent, and democrat and religious affiliations were recoded to reflect whether participants identified with a religious tradition or identified as nonreligious. Participants were next asked to report their level of trust in science using a feeling thermometer with a scale that ranged from 0 (no trust at all) to 10 (complete trust). This method is commonly used to assess attitudes toward groups of people, political figures, and institutions (Hetherington, 1998; Lavrakas, 2008; Miller et al., 2004). To capture beliefs about the media, we also asked participants whether they believe the media is accurately portraying the risks of the coronavirus and response options asked participants to agree or disagree with the statement (Rubin et al., 2009).

Xenophobia was measured using four items taken from Hjerm (2001). The items asked participants to rate the extent 
to which they believe immigrants increase crime rates, are good for the United States' economy (reverse scored), take jobs away from people who were born in the U.S., and make the U.S. more open to new ideas and cultures (reverse scored). The response scale ranged from 1 (strongly disagree) to 5 (strongly agree). This measure has been used to assess xenophobia across a variety of countries and scores on this measure have been found to be related to a number of theoretically relevant variables (e.g., Hayes \& Dowds, 2006; Hjerm, 2001, 2007, 2009). The xenophobia scale also demonstrated adequate reliability in our sample $(\alpha=0.77)$.

In addition to measuring sociopolitical characteristics that may influence perceptions of the virus, we also included the per capita death rate for the state in which one resided to control for objective indicators of risk. To account for per capita death rate, our collected data were merged with data taken from USAFacts which compiles data from state health departments (USAFacts, 2020). For each participant, the state in which they resided was matched to the per capita death rate, measured as deaths per 100,000 residents, in that state at the time the survey was administered (March 12).

In accordance with the health belief model (Carpenter, 2010; Rosenstock, 1974), we next measured perceptions of the severity of the virus. This was measured with a single item that asked participants to rate their agreement with the statement, "the coronavirus is a serious disease" (Rubin et al., 2009, 2010). Participants were asked to respond on a scale of 1 (strongly disagree) to 5 (strongly agree). We also measured two additional potential mechanisms that have been advanced by previous research: fear of the virus and knowledge about how the virus is transmitted. Fear of contracting COVID-19 was measured with a single item (i.e., "How would you rate your fear of getting coronavirus?") and responses ranged from 1 (no fear at all) to 10, (extreme fear). Knowledge about COVID-19 was measured using a scale created for this study which assessed the accuracy of participants' knowledge of the origin, treatment, transmission, and symptoms of the virus. There were 10 items that assessed general knowledge of the availability of a treatment or cure for the virus, the origin of the virus, the mortality rate of the virus, and the expected duration of the virus. There were an additional 6 items that asked about the ways the virus can spread and 8 items about the common symptoms. These items parallel measures used to assess knowledge about previous outbreaks such as the avian flu (Di Giuseppe et al., 2008) and were adapted using fact sheets created by health organizations to address common misconceptions about COVID-19 (Maragakis, 2020; WHO, 2020).

Health behaviors included measures that assessed whether participants modified their behaviors in response to the virus, whether participants prepared for the virus by purchasing extra supplies, and how frequently participants washed their hands. Each health behavior was measured using a single item that asked participants to report whether they had modified their habits for fear of getting the coronavirus, whether they purchased extra food or supplies in response to the coronavirus, and how frequently they washed their hands before eating (Goodwin et al., 2009; Rubin et al., 2009, 2010). Response options for behavioral modifications and preparations were yes/no whereas the response scale for handwashing ranged from 1 (never) to 5 (always).

\section{Analyses}

The relationships between the social predictors; perceptions of severity, fear, and knowledge of COVID-19; and health behaviors were tested using a path model in LISREL 9.30. The structure of the path model was informed by the health belief model and motivational theories of health behaviors, which together posit that social and demographic characteristics predict perceived severity, knowledge, and fear, which then shape health behaviors. Correspondingly, and as shown in Fig. 1, our model included paths from the social predictors (i.e., political affiliation, religiousness, xenophobia, trust in media, trust in science, and the per capita death rate) to perceptions of fear, seriousness, and knowledge of COVID-19 as well as paths from these three variables to the health behaviors (i.e., modified behaviors, preparations, and handwashing).

We examined the model by first assessing model fit using the following fit statistics: chi square $\left(\chi^{2}\right)$, root mean square error of approximation (RMSEA), comparative fit index (CFI), non-normed fit index (NNFI), and standardized root mean squared residual (SRMR). The relationships among the variables were then assessed by interpreting the significance of the path coefficients. We finally calculated indirect effects from the social characteristics to the health behaviors through perceived severity, fear, and knowledge. The significance of the indirect effects was assessed by calculating a bootstrapped confidence interval around the indirect effect using a Monte Carlo simulation with 20,000 repetitions. We concluded that the indirect effect was significant if the bootstrapped confidence interval did not contain zero.

\section{Results}

\section{Descriptive statistics}

Means and standard deviations for study variables are displayed in Table 1. Examining the trust variables, on average, participants reported relatively high trust in science $(M=7.47, S D=2.48)$. However, the sample was roughly evenly split on their perceptions of whether or not the media was accurately portraying the coronavirus $(53.8 \%$ agreed; 


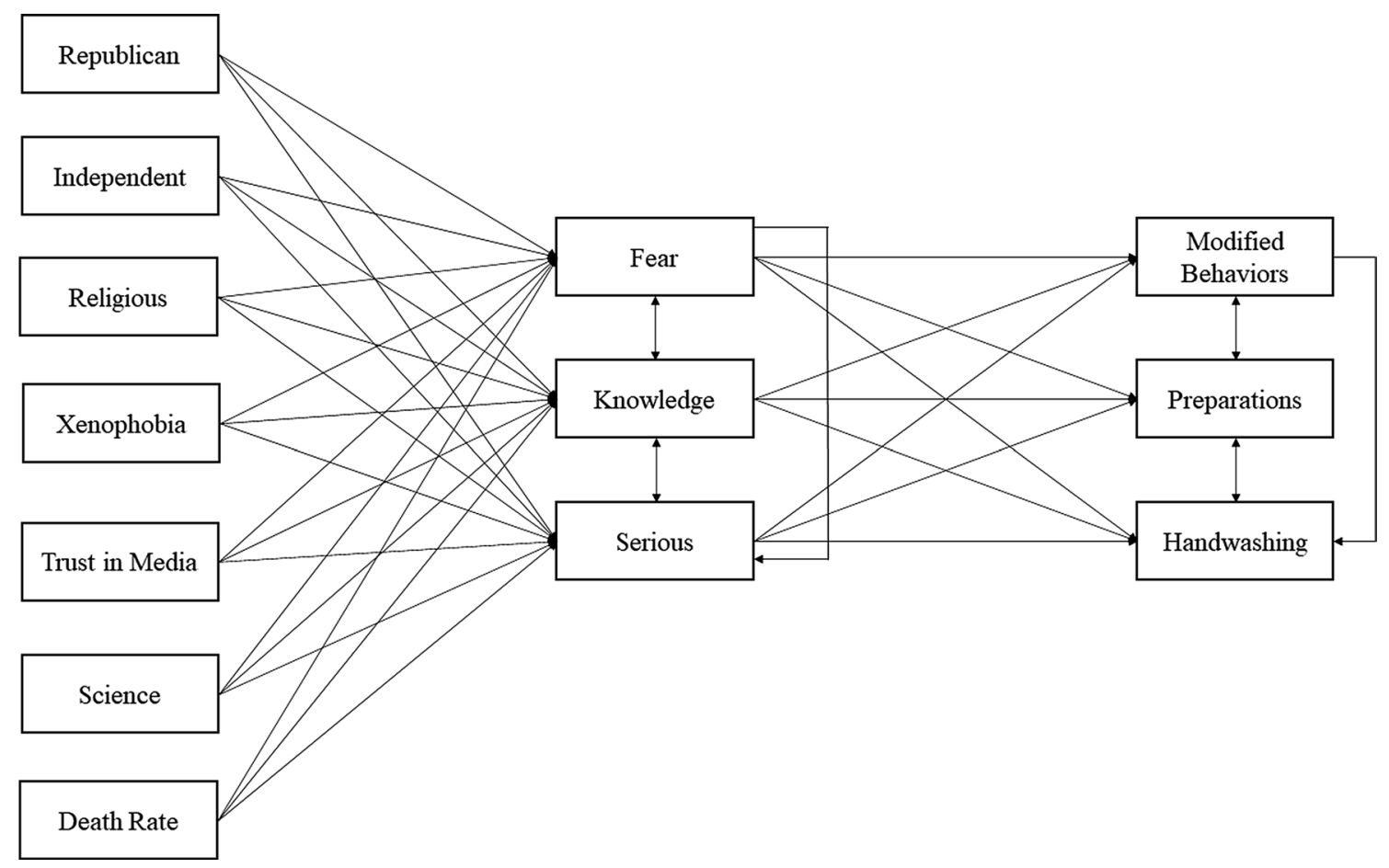

Fig. 1 The conceptual model of social factors, health beliefs, and health behaviors

Table 1 Descriptive statistics $(\mathrm{N}=1141)$

\begin{tabular}{llcc}
\hline Variable & Range/Coding & Mean & SD \\
\hline Republican & $\begin{array}{l}0=\text { No } \\
1=\text { Yes }\end{array}$ & 0.28 & 0.45 \\
Independent & $\begin{array}{l}0=\text { No } \\
1=\text { Yes }\end{array}$ & 0.29 & 0.45 \\
Religious & $0=$ Non-religious & 0.72 & 0.45 \\
& $\begin{array}{l}1=\text { Religious } \\
\text { Deaths per capita }\end{array}$ & 0.407 & \\
Media & $1=$ No & 0.015 & 0.068 \\
Total knowledge & 2 $=$ Yes & 1.54 & 0.50 \\
Xenophobia & $1-5$ & & \\
Trust in science & $0-10$ & 17.29 & 2.74 \\
Preparations & $0=$ No & 2.61 & 0.95 \\
& $1=$ Yes & 7.47 & 2.48 \\
Modified Behaviors & $0=$ No & 0.56 & 0.50 \\
Handwashing & $1=$ Yes & & \\
\hline
\end{tabular}

Deaths per capita measured as the number of deaths per 100,000 state residents

$M=0.54, S D=0.50)$. Further, the average score on the xenophobia scale was $2.61(S D=0.95)$. Moving to perceived severity, knowledge, and fear, participants tended to agree that COVID-19 is a serious disease $(M=4.19, S D=1.12)$ and reported a moderate level of fear of contracting the virus
$(M=5.85, S D=2.76)$. On average, participants scored 17.29 $(S D=2.74)$ out of a total of 24 possible points on the knowledge of COVID-19 checklist. Perceived seriousness, fear, knowledge, and health behaviors also varied by geographic location in the United States, but to a different extent. There is considerably more variation in perceived seriousness and fear between states than there is variation in handwashing practices or decisions to modify behaviors relative to COVID-19. See Fig. 2 for a geographic distribution of key health beliefs across U.S. states.

For the health behaviors, the majority of participants reported they had modified their habits out of a fear of contracting COVID-19 (71\% said yes; $M=1.29, S D=0.45$ ) whereas just over half of our participants reported they had bought food or supplies to prepare for the coronavirus ( $56.3 \%$ said yes; $M=1.44, S D=0.50$ ). Finally, our participants reported frequently washing their hands before eating $(M=4.29, S D=0.94)$.

\section{Path model results}

The model in which the social characteristics predicted perceived severity, knowledge, and fear, and these factors in turn predicted health behaviors demonstrated good fit $\left(\chi^{2}(21)=54.44, p<0.001, \mathrm{RMSEA}=0.037, \mathrm{CFI}=0.981\right.$, $\mathrm{NNFI}=0.929, \mathrm{SRMR}=0.022)$. We next examined the path coefficients to determine which relationships were 

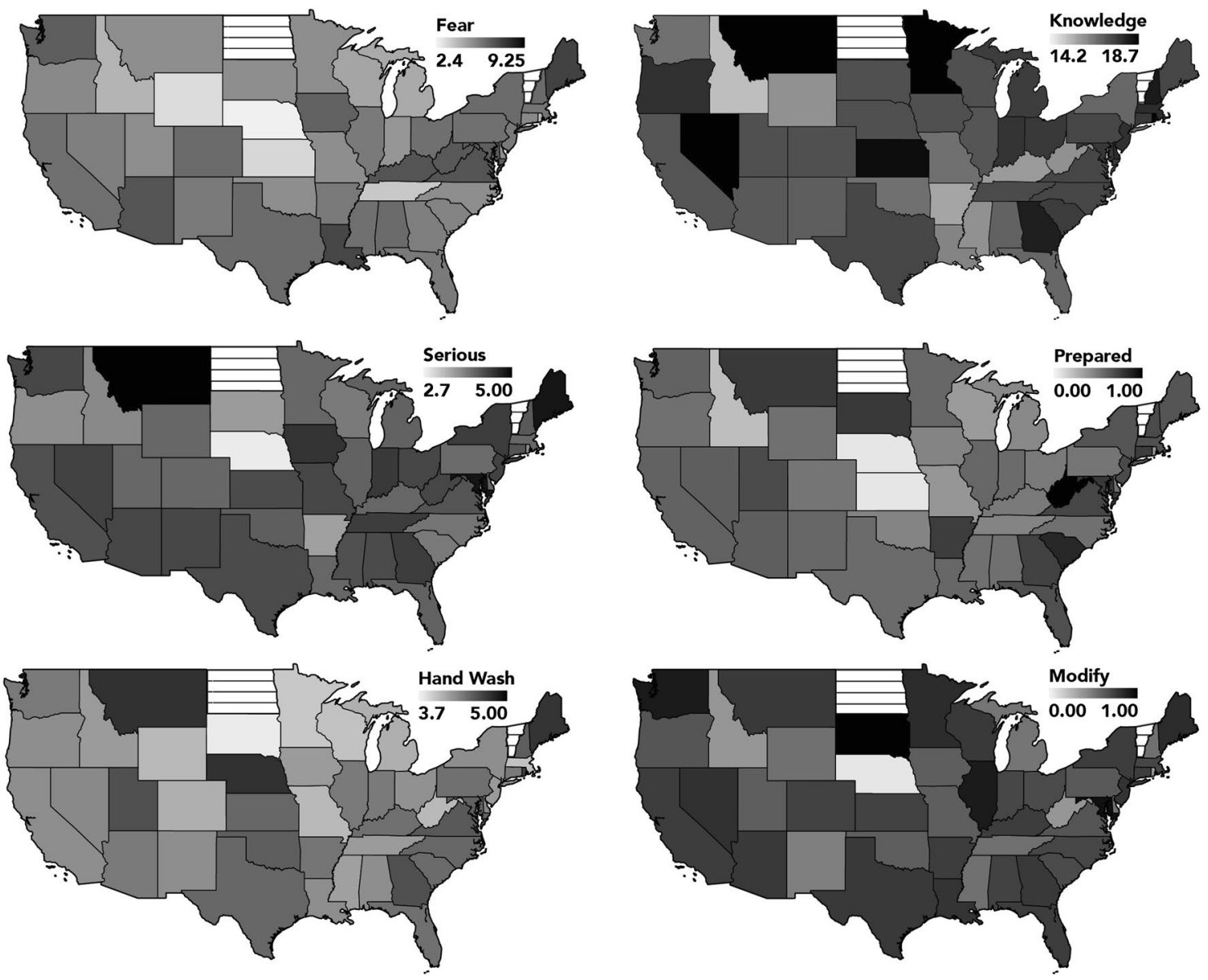

Fig. 2 Geographic variation in key health beliefs and behaviors

significant (Table 2). Results suggest that identifying one's political affiliation as republican $(\gamma=-0.15, p<0.05)$ and independent $(\gamma=-0.12, p<0.05)$ were significantly negatively associated with fear of the virus. Religiousness was positively related to fear $(\gamma=0.09, p<0.05)$ and perceptions of seriousness $(\gamma=0.11, p<0.05)$, but negatively related to knowledge $(\gamma=-0.11, p<0.05)$. Xenophobia was associated with increased fear $(\gamma=0.17, p<0.05)$, lower seriousness ratings $(\gamma=-0.10, p<0.05)$, and decreased knowledge $(\gamma=-0.16, p<0.05)$. Trust in media and science were both positively related to fear $(\gamma=0.19, p<0.05 ; \gamma=0.10$, $p<0.05)$ and seriousness $(\gamma=0.14, p<0.05 ; \gamma=0.14$, $p<0.05)$. Trust in science was additionally positively associated with knowledge of COVID-19 $(\gamma=0.16, p<0.05)$.

Examining the relationships between perceived severity, knowledge, and fear, and health behaviors showed that fear was positively related to behavioral modifications $(\beta=0.26$, $p<0.05)$, preparations $(\beta=0.37, p<0.05)$, and increased handwashing $(\beta=0.09, p<0.05)$. Perceptions of seriousness were also significantly positively related to behavioral modifications $(\beta=0.12, p<0.05)$ and handwashing $(\beta=0.11, p<0.05)$. Finally, knowledge positively predicted

Table 2 Coefficients from the model of social factors, health beliefs, and health behaviors

\begin{tabular}{|c|c|c|c|}
\hline & \multicolumn{3}{|l|}{ Health beliefs } \\
\hline & Fear & Serious & Knowledge \\
\hline \multicolumn{4}{|c|}{ Social characteristics } \\
\hline Republican & $\begin{array}{r}-0.154^{*} \\
(0.032)\end{array}$ & $-0.030(0.033)$ & $0.013(0.034)$ \\
\hline Independent & $\begin{array}{r}-0.124^{*} \\
(0.030)\end{array}$ & $-0.045(0.031)$ & $0.011(0.032)$ \\
\hline Xenophobia & $0.172 *(0.032)$ & $\begin{array}{r}-0.100^{*} \\
(0.033)\end{array}$ & $-0.160 *(0.033)$ \\
\hline Religious & $0.092 *(0.028)$ & $0.106 *(0.029)$ & $-0.113 *(0.029)$ \\
\hline Trust in media & $0.194 *(0.028)$ & $0.138 *(0.028)$ & $-0.049(0.029)$ \\
\hline Trust in science & $0.102 *(0.030)$ & $0.135^{*}(0.031)$ & $0.164 *(0.031)$ \\
\hline Death rate & $0.031(0.027)$ & $0.010(0.028)$ & $-0.053(0.028)$ \\
\hline \multicolumn{4}{|l|}{ Health behaviors } \\
\hline $\begin{array}{l}\text { Modified } \\
\text { behaviors }\end{array}$ & $0.258 *(0.029)$ & $0.119 *(0.028)$ & $0.091 *(0.026)$ \\
\hline Preparations & $0.368 *(0.029)$ & $-0.002(0.030)$ & $-0.006(0.029)$ \\
\hline Handwashing & $0.094 *(0.031)$ & $0.109 *(0.031)$ & $0.103 *(0.030)$ \\
\hline
\end{tabular}

(a) $* p<0.05$; (b) standard errors are reported in parentheses 
behavioral modifications $(\beta=0.09, p<0.05)$ and handwashing $(\beta=0.10, p<0.05)$.

We further computed the indirect effects from each of the social characteristics to the health behaviors through perceived severity, knowledge, and fear and the indirect effects are shown in Table 3.

Looking at the general themes that emerged, all of the social characteristics had significant indirect effects on at least one of the health behaviors. Further, the effects of social characteristics on health behaviors were most strongly transmitted through perceptions of fear of contracting COVID-19. Finally, xenophobia, religiousness, and trust in science had significant indirect effects on modified behaviors and handwashing through all three health beliefs, which highlights the importance of these social characteristics in particular as there are multiple pathways through which they can affect health behaviors.

\section{Discussion}

The current paper integrated literature on the health belief model, contested illnesses, and social determinants of health perceptions and behaviors to examine the influence of social factors on perceptions of, knowledge about, and behavioral responses to COVID-19. Consistent with the health belief model, our findings reinforce the connection between beliefs about the perceived severity of a disease and one's engagement in preventive behaviors. Our findings also underscore that such beliefs and behaviors are informed by the social, cultural, and political contexts in which COVID-19 is constructed as a legitimate public health threat. We found that perceived severity, knowledge, and fear were predicted by political affiliation, religiosity, xenophobia, trust in the media, and trust in science. It is also worth noting that perceived severity, knowledge, and fear related to COVID-19 were related to these social and political factors independent of the number of deaths per capita in one's state of residence. In other words, beliefs and knowledge are associated with social and political factors that may influence subjective appraisals of an infectious disease even after accounting for an objective indicator of the local risk of the virus.

It is possible that other indicators of risk such as the case fatality rate (i.e. the number of deaths that occur among documented COVID-19 cases) or the infection fatality rate (i.e. the number of deaths that occur among all infections) would be related to beliefs and knowledge about COVID-19 since they provide estimates of individual risk if infected.

Table 3 Indirect effects of the social factors on health behaviors through health beliefs

\begin{tabular}{|c|c|c|c|}
\hline & \multicolumn{3}{|l|}{ Indirect effects $[95 \% \mathrm{CI}]$} \\
\hline & Fear & Serious & Knowledge \\
\hline Republican Modified behaviors & $-0.040 *[-0.058,-0.023]$ & $-0.004[-0.012,0.003]$ & $0.001[-0.004,0.007]$ \\
\hline Republican Preparations & $-0.057 *[-0.081,-0.034]$ & $0.000[-0.003,0.003]$ & $0.000[-0.002,0.002]$ \\
\hline Republican Handwashing & $-0.014 *[-0.026,-0.005]$ & $0.003[-0.011,0.003]$ & $0.001[-0.004,0.008]$ \\
\hline Independent Modified behaviors & $-0.032 *[-0.050,-0.016]$ & $-0.005[-0.014,0.002]$ & $0.001[-0.005,0.007]$ \\
\hline Independent Preparations & $-0.045^{*}[-0.069,-0.023]$ & $0.000[-0.003,0.003]$ & $0.000[-0.002,0.002]$ \\
\hline Independent Handwashing & $-0.012 *[-0.022,-0.004]$ & $-0.005[-0.013,0.001]$ & $0.001[-0.005,0.008]$ \\
\hline Xenophobia Modified behaviors & $0.044 *[0.027,0.064]$ & $-0.012 *[-0.022,-0.004]$ & $-0.015^{*}[-0.027,-0.005]$ \\
\hline Xenophobia Preparations & $0.063 *[0.040,0.088]$ & $0.000[-0.006,0.007]$ & $0.001[-0.009,0.011]$ \\
\hline Xenophobia Handwashing & $0.016 *[0.006,0.029]$ & $-0.011 *[-0.021,-0.003]$ & $-0.016^{*}[-0.029,-0.006]$ \\
\hline Religious Modified behaviors & $0.024 *[0.008,0.041]$ & $0.013 *[0.004,0.023]$ & $-0.010 *[-0.020,-0.003]$ \\
\hline Religious Preparations & $0.033 *[0.012,0.057]$ & $0.000[-0.007,0.006]$ & $0.001[-0.006,0.008]$ \\
\hline Religious Handwashing & $0.008 *[0.002,0.018]$ & $0.012 *[0.004,0.022]$ & $-0.012 *[-0.022,-0.004]$ \\
\hline Trust in media Modified behaviors & $0.050 *[0.032,0.070]$ & $0.016^{*}[0.007,0.028]$ & $-0.004[-0.012,0.001]$ \\
\hline Trust in media Preparations & $0.071 *[0.048,0.097]$ & $0.000[-0.009,0.008]$ & $0.000[-0.003,0.004]$ \\
\hline Trust in media Handwashing & $0.018 *[0.006,0.032]$ & $0.015 *[0.006,0.027]$ & $-0.005[-0.013,0.001]$ \\
\hline Trust in science Modified behaviors & $0.026^{*}[0.011,0.043]$ & $0.016^{*}[0.007,0.028]$ & $0.015 *[0.005,0.027]$ \\
\hline Trust in science Preparations & $0.038 *[0.016,0.060]$ & $0.000[-0.009,0.008]$ & $-0.001[-0.011,0.009]$ \\
\hline Trust in science Handwashing & $0.010 *[0.003,0.019]$ & $0.015^{*}[0.006,0.026]$ & $0.017 *[0.007,0.029]$ \\
\hline Death rate Modified behaviors & $0.008[-0.007,0.024]$ & $0.001[-0.006,0.009]$ & $-0.005[-0.012,0.000]$ \\
\hline Death rate Preparations & $0.011[-0.010,0.033]$ & $0.000[-0.002,0.002]$ & $0.000[-0.003,0.004]$ \\
\hline Death rate Handwashing & $0.003[-0.003,0.010]$ & $0.001[-0.006,0.008]$ & $-0.005[-0.013,0.001]$ \\
\hline
\end{tabular}

(a) $* p<0.05$; (b) $95 \%$ confidence intervals appear in parentheses; (c) confidence intervals around the indirect effects were calculated using a bootstrapping technique with 20,000 iterations 
Our data, however, suggest that the overall number of deaths within one's state, adjusted for population, are not closely related to whether individuals perceive COVID-19 as a threat. These findings lend support for integrating a broad range of social characteristics into models of health beliefs and behaviors, in addition to measures of risk, to identify people who may be more likely to contest the legitimacy of COVID-19.

Importantly, these same social and political factors also predict individual engagement in health behaviors, including social distancing and handwashing and decisions to stock up on household items. Together these data suggest that social and political characteristics may act as critical public health barriers that prevent some populations from taking appropriate protective actions and should be integrated into conceptual models and empirical studies of health-related perceptions and behaviors. The linkages between fear and knowledge and health behaviors also provides support for prior conceptual and empirical work which has emphasized knowledge as a key barrier to protective health behaviors (Bish et al., 2011; Castro-Sánchez et al., 2016; Velan et al., 2011) and argued for the inclusion of fear in explorations of health beliefs and behaviors (Champion et al., 2005; Rogers $\&$ Prentice-Dunn, 1997). We note that the health protective practices measured in our study vary in efficacy for preventing transmission of respiratory illnesses such as COVID-19 but have been recommended during the COVID-19 pandemic (Centers for Disease Control, 2020). For example, there is evidence that isolation, testing, and contact tracing can successfully reduce COVID-19 transmission (Kucharski et al., 2020), while handwashing is generally less effective for respiratory as compared to gastrointestinal illnesses (Aiello et al., 2008). Although there is less evidence that purchasing household items is successful for mitigating COVID-19 transmission, we include this as our data were collected at a time when public health agencies were encouraging people to limit the time spent outside of their homes and stocking up on supplies could help minimize unnecessary public exposure.

Our findings on political affiliation support previous evidence that political ideology shapes fear of contracting COVID-19 (Calvillo et al., 2020; Medina \& Gebeloff, 2020) and other illnesses (Baumgaertner et al., 2018). We propose that political affiliation is related to fear of COVID-19 and health behaviors because of the deep political divides in the information one is exposed to and the relative priorities for protecting economic versus physical well-being. Some of the most prominent political debates surrounding COVID-19 have centered on the extent to which the virus poses a credible public health threat in addition to the most appropriate federal, state, and local responses necessary to limit transmission (Grisales, 2020). In particular, political differences have emerged regarding social distancing recommendations such as when to reopen businesses and restart the economy, and whether to require the use of masks in public places (McCarthy, 2020). There is evidence to suggest that political divides in fear of COVID-19 infection stem from infection rates which disproportionately affected areas with a higher concentration of Democrats earlier on in the pandemic (Medina \& Gebeloff, 2020). Our results, however, suggest that higher death rates cannot fully account for whether individuals fear infection from COVID-19.

Although political affiliation has received a great deal of attention in popular press efforts to explain variation in COVID-19 attitudes, knowledge, and behaviors, we find that other social factors are also salient. After controlling for the effect of political affiliation, trust in information sources predicted perceptions of severity, fear, and knowledge, and subsequently impacted the adoption of effective protective health behaviors such as handwashing and behavior modifications, including efforts to social distance. Of particular interest is the finding that individuals who do not trust the media to provide factual information were less likely to fear contracting the virus or believe that it was serious and thus were less likely to take preventative measures. Given that many media outlets have emphasized the severity of the outbreak, mistrusting the media may also lead people to downplay the severity and express lower fear of the virus. Trust in science was associated with these same beliefs, and also predicted knowledge of COVID-19. The culmination of these findings suggests that lack of trust in media and science seem to be critical barriers to increasing the adoption of preventive health behaviors.

Beyond political affiliation and trust in information sources, the fact that both religious affiliation and xenophobia predicted perceived severity, knowledge, and fear is important. Individuals who self-identified with a religious tradition were more likely to fear contracting COVID-19 and to take it seriously and these effects extended to health behaviors such as adopting new habits and engaging in more frequent handwashing. Although religious identification was associated with lower knowledge, this did not result in lower protective behaviors which may stem from cultural norms in religious communities that emphasize trust in doctors and medicine (Benjamins, 2006; Mansfield et al., 2002). There is considerable evidence that religious individuals in the United States are more likely to trust their doctor than their nonreligious counterparts and are more likely to engage in preventive health service use such as receiving mammograms (Benjamins, 2006; Benjamins et al., 2006; Langlie, 1977). We also found significant relationships between xenophobia and perceived severity, knowledge, and fear, which had indirect effects on the adoption of health protective behaviors. We posit that xenophobia may be associated with increased fear of COVID-19 because it has been framed as a "foreign" threat and perceptions of the threat of the virus 
may be exacerbated by negative feelings toward foreigners more generally.

\section{Public health implications}

This study has implications for public health because, like other infectious diseases, a successful response to the unfolding COVID-19 pandemic requires a robust public health response and a willingness among individuals to adopt health behaviors. Our findings suggest that beliefs that COVID-19 poses a serious threat to one's health, fear of the virus, and knowledge of the virus are related to social, political, and demographic factors. As a result, it is critical to understand the social factors that reduce the likelihood that the virus will be taken seriously and that appropriate mitigation tactics will be used. Given political divides in the United States, public health practitioners should prioritize providing health information that underscores the severity of COVID-19 especially among subgroups who may be less likely to fear infection or take the virus seriously, and subsequently adopt protective behaviors such as social distancing or wearing a mask. Unfortunately, providing evidence alone is unlikely to be effective in light of the competing spread of misinformation (Jayant Limaye et al., 2020) and degrading trust in political, scientific, and public health leadership (Gallup Historical Trends, 2020). Building on successful infectious disease campaigns in the U.S. and international settings, public health efforts will have to additionally focus on rebuilding trust and may consider utilizing community-based approaches to effectively share information about COVID-19 (Christopher, 2008; Hamel et al., 2020; Schoch-Spana, 2017). Our findings suggest that religious communities may be effective at encouraging the adoption of health protective behaviors and there may be benefits to public health agencies collaborating with religious organizations and other community groups who may have more trust among community members and better understand local norms. These efforts may successfully reinforce collective behavior changes to stem transmission of COVID-19.

\section{Limitations and future research}

We used a large national sample of residents in the United States and as such, our findings are limited to this population. Beyond the U.S. context, our findings may not be applicable as political debates that have surrounded the response to COVID-19 may be unique to this context. Another important limitation is that our measures of health protective behaviors are self-reported and therefore may not reflect actual behaviors (Newell et al., 1999). That is, some respondents may have overreported the extent to which they engaged in public health behaviors due to social desirability bias and future work on COVID-19 should seek to establish objective measures of health behaviors. A third limitation is that data were collected in March 2020 when participants were still learning about the novel coronavirus and best practices to reduce transmission. Much has changed in the months since data were collected as the pandemic has continued to unfold. As such, it is possible that the relationships between social factors and health behaviors have also changed in response to newly available information and/or treatments. Relatedly, the measure used to assess COVID19 knowledge does not capture advancements in our understanding of the disease since March 2020 and it is possible that, as information about COVID-19 has accrued, it has produced greater variance in the public's knowledge which may make knowledge a more important predictor of subsequent behavioral responses.

Another limitation is that not all social factors could be included in this survey and therefore we were not able to explain all variation in health beliefs and behaviors in the United States. Future research should explore additional social factors and utilize qualitative methods to better understand how individual decisions to engage in health protective behaviors are shaped by their social position. In addition, Hispanic Americans were underrepresented in our sample. Given that Hispanic Americans have been harder hit by COVID-19 than White Americans (CDC, 2020b), it is possible that Hispanics might have different perceptions of the severity and different levels of fear surrounding COVID-19. However, there is not currently evidence which suggests that race/ethnicity would change the nature of the relationships among the focal variables included in our model. Future research could address this possibility by further exploring the impact of race/ethnicity on the relationships between health beliefs and health behaviors, particularly for groups that have been the most severely affected by COVID-19.

A final limitation is that our approach utilized a path model to understand the relationship between social factors, beliefs, attitudes, knowledge, and behaviors, which assumes causal relationships. Because we cannot establish causality with cross-sectional survey data, it is not possible to confirm that the relationships are indeed causal or that the relationships are in the direction proposed by our model. We note that he stable nature of the social predictors included in our model and the novelty of beliefs and behaviors related to COVID-19 supports the assumption that social characteristics are antecedent to the remaining variables in our model. However, it is possible that health beliefs do not proceed health behavior. For example, it is possible that individuals who have adopted handwashing, social distancing, or other health protective behaviors may believe, as a result, that the virus is more severe or that engaging in these behaviors may activate or make more salient participants' fear of the virus. 
The direction of the modeled relationships does comport with theoretical models of health beliefs and behaviors, but additional research is needed to confirm directionality.

\section{Conclusion}

COVID-19 remains a formidable threat to public health in the United States and in many countries worldwide. Despite continued disease transmission, there are also persistent and substantial divides in fear, knowledge, and perceptions of the severity of the virus, that are associated with behavioral responses that may help to curb the pandemic. Our findings suggest that social, political, and demographic factors help us understand differences in how individuals perceive the threat of COVID-19 infection and make decisions to adopt evidence-based health protective behaviors. Although some of these factors, such as political affiliation, have been underscored in mainstream media, other factors are salient as well and will be necessary to consider as officials continue to develop effective public health responses to COVID-19.

Author contributions Both authors contributed to the study conception and design, data collection and analysis, and manuscript writing. Both authors read and approved the final manuscript.

Funding The authors received no financial support for the research, authorship, and/or publication of this article.

\section{Declarations}

Conflict of interests Berkeley Franz and Lindsay Y. Dhanani declare that there is no conflict of interest.

Consent to participate Informed consent was obtained from all individual participants included in the study.

Ethical approval The questionnaire and methodology for this study was approved by the Institutional Review Board at Ohio University.

Human and Animal Rights and Informed Consent All procedures followed were in accordance with ethical standards of the responsible committee on human experimentation (institutional and national) and with the Helsinki Declaration of 1975, as revised in 2000. Informed consent was obtained from all patients for being included in the study.

\section{References}

Aiello, A. E., Coulborn, R. M., Perez, V., \& Larson, E. L. (2008). Effect of hand hygiene on infectious disease risk in the community setting: A meta-analysis. American Journal of Public Health, 98, $1372-1381$
Alsan, M., Stantcheva, S., Yang, D., \& Cutler, D. (2020). Disparities in coronavirus 2019 reported incidence, knowledge, and behavior among US adults. JAMA Network Open, 3, e2012403

Anderson, J. A., \& Bartkus, D. E. (1973). Choice of medical care: A Behavioral Model of Health and Illness Behavior. Journal of Health and Social Behavior, 14, 348-362

Barrios, J. M., \& Hochberg, Y. (2020). Risk Perception Through the Lens of Politics in the Time of the COVID-19 Pandemic. National Bureau of Economic Research.

Baumgaertner, B., Carlisle, J. E., \& Justwan, F. (2018). The influence of political ideology and trust on willingness to vaccinate. PLOS ONE, 13, 1-13

Benjamins, M. R. (2006). Religious influences on trust in physicians and the health care system. International Journal of Psychiatry in Medicine, 36, 69-83

Benjamins, M. R., Trinitapoli, J., \& Ellison, C. G. (2006). Religious attendance, health maintenance beliefs, and mammography utilization: Findings from a nationwide survey of Presbyterian women. Journal for the Scientific Study of Religion, 45, 597-607

Bish, A., Yardley, L., Nicoll, A., \& Michie, S. (2011). Factors associated with uptake of vaccination against pandemic influenza: A systematic review. Vaccine, 29, 6472-6484

Calvillo, D. P., Ross, B. J., Garcia, R. J. B., Smelter, T. J., \& Rutchick, A. M. (2020). Political ideology predicts perceptions of the threat of COVID-19 (and susceptibility to fake news about it). Social Psychological and Personality Science, 11, 1119-1128

Carpenter, C. J. (2010). A meta-analysis of the effectiveness of health belief model variables in predicting behavior. Health Communication, 25, 661-669

Castro-Sánchez, E., Chang, P. W. S., Vila-Candel, R., Escobedo, A. A., \& Holmes, A. H. (2016). Health literacy and infectious diseases: Why does it matter? International Journal of Infectious Diseases, $43,103-110$

CDC. (2020a). Coronavirus: How to protect yourself \& others. Retrieved June 25, 2020, https://www.cdc.gov/coronavirus/2019ncov/prevent-getting-sick/prevention.html

CDC. (2020b). COVID-19 hospitalization and death by race/ethnicity. Retrieved October 13, 2020, https://www.cdc.gov/coronavirus/ 2019-ncov/covid-data/investigations-discovery/hospitalizationdeath-by-race-ethnicity.html

Centers for Disease Control. (2020). Social distancing, quarantine, and isolation. Coronavirus Disease 2019 (COVID-19). Retrieved May 26, 2020, https://www.cdc.gov/coronavirus/2019-ncov/preventgetting-sick/social-distancing.html

Champion, V., Skinner, C. S., \& Menon, U. (2005). Development of a self-efficacy scale for mammography. Research in Nursing and Health, 28, 329-336

Cheng, S. O. (2020). Xenophobia due to the coronavirus outbreak: A letter to the editor in response to "the socio-economic implications of the coronavirus pandemic (COVID-19) - A review.' International Journal of Surgery, 79, 13-14

Christopher, S., Watts, V., McCormick, A. K. H. G., \& Young, S. (2008). Building and maintaining trust in a community-based participatory research partnership. American Journal of Public Health, 98, 1398-1406

Conrad, P., \& Barker, K. K. (2010). The social construction of illness: Key insights and policy implications. Journal of Health and Social Behavior, 51, S67-S79

de Bruin, W. B., \& Bennett, D. (2020). Relationships between initial COVID-19 risk perceptions and protective health behaviors: A national survey. American Journal of Preventive Medicine, 59, $157-167$

Faust, J. S., \& Del Rio, C. (2020). Assessment of deaths from COVID19 and from seasonal influenza. JAMA Internal Medicine, 180, $1045-1046$ 
Gallup Historical Trends. (2020). Confidence in institutions. In depth: Topics A to Z. Retrieved December 14, 2020, https:// news.gallup.com/poll/1597/confidence-institutions.aspx

Giuseppe, Di., Gabriella, R. A., Albano, L., Marinelli, P., \& Angelillo, I. F. (2008). A survey of knowledge, attitudes and practices towards avian influenza in an adult population of Italy. BMC Infectious Diseases, 8, 36

Gollwitzer, A., Martel, C., Brady, W. J., Pärnamets, P., Freedman, I. G., Knowles, E. D., \& Van Bavel, J. J. (2020). Partisan differences in physical distancing are linked to health outcomes during the COVID-19 Pandemic. Nature Human Behaviour, 4, 1186-1197

Gondi, S., Beckman, A. L., Deveau, N., Raja, A. S., Ranney, M. L., Popkin, R., \& He, S. (2020). Personal protective equipment needs in the USA during the COVID-19 pandemic. The Lancet, 395, e90-91

Goodwin, R., Haque, S., Neto, F., \& Myers, L. B. (2009). Initial psychological responses to influenza A, H1N1 ('Swine Flu'). BMC Infectious Diseases, 9, 166

Grisales, C. (2020). Coronavirus debate to reopen: Congress faces A partisan divide. NPR. Retrieved June 25, 2020, https://www.npr. org/2020/05/15/852359651/debate-over-reopening-house-of-repre sentatives-tests-a-partisan-flashpoint

Hamel, L., Audrey, K., Ashley, K., Lunna, L., Cailey, M., \& Mollyann, B. (2020). KFF Health tracking poll - September 2020: Top issues in 2020 election. The role of misinformation, and views on a potential coronavirus vaccine I KFF. Kaiser Family Foundation. Retrieved December 14, 2020, https://www.kff.org/coronaviruscovid-19/report/kff-health-tracking-poll-september-2020/

Hayes, B., \& Dowds, L. (2006). Social contact, cultural marginality or economic self-interest? Attitudes towards immigrants in Northern Ireland. Journal of Ethnic and Migration Studies, 32, 455-476

Hetherington, M. J. (1998). The political relevance of political trust. American Political Science Review., 92, 791-808

Hjerm, M. (2001). Education, xenophobia and nationalism: A comparative analysis. Journal of Ethnic and Migration Studies, 27, 37-60

Hjerm, M. (2007). Do numbers really count? Group threat theory revisited. Journal of Ethnic and Migration Studies, 33, 1253-1275

Hjerm, M. (2009). Anti-immigrant attitudes and cross-municipal variation in the proportion of immigrants. Acta Sociologica, 52, 47-62

Hornsey, M. J., Finlayson, M., Chatwood, G., \& Begeny, C. T. (2020). Donald trump and vaccination: The effect of political identity, conspiracist ideation and presidential tweets on vaccine hesitancy. Journal of Experimental Social Psychology, 88, 103947

Janz, N. K., \& Becker, M. H. (1984). The health belief model: A decade later. Health Education \& Behavior, 11, 1-47

Johns Hopkins University. (2020). Johns Hopkins coronavirus resource center. Retrieved June 25, 2020, https://coronavirus.jhu.edu/

Johns Hopkins Coronavirus Resource Center. (2020). Mortality Analyses. Maps and Trends. Retrieved December 1, 2020, https://coron avirus.jhu.edu/data/mortality

Kucharski, A. J., Klepac, P., Conlan, A. J. K., Kissler, S. M., Tang, M. L., Fry, H., Gog, J. R., John Edmunds, W., Emery, J. C., Medley, G., Munday, J. D., Russell, T. W., Leclerc, Q. J., Diamond, C., Procter, S. R., Gimma, A., Sun, F. Y., Gibbs, H. P., Rosello, A., ... Simons, D. (2020). Effectiveness of isolation, testing, contact tracing, and physical distancing on reducing transmission of SARSCoV-2 in different settings: A mathematical modelling study. The Lancet Infectious Diseases, 20, 1151-1160

Langlie, J. K. (1977). Social networks, health beliefs, and preventive health behavior. Journal of Health and Social Behavior, 18, 244-260

Lavrakas, P. J. (2008). Feeling thermometer. Encyclopedia of Survey Research Methods

Limaye, R. J., Sauer, M., Ali, J., Bernstein, J., Wahl, B., Barnhill, A., \& Labrique, A. (2020). Building trust while influencing online
COVID-19 content in the social media world. Lancet Digital Health, 2, e277-e278

Mansfield, C. J., Mitchell, J., \& King, D. E. (2002). The doctor as god's mechanic? Beliefs in the Southeastern United States. Social Science and Medicine, 54, 399-409

Maragakis, L. L. (2020). Coronavirus at a glance: infographic. Johns Hopkins Medicine. Retrieved June 25, 2020, https://www.hopki nsmedicine.org/health/conditions-and-diseases/coronavirus/coron avirus-facts-infographic

McCarthy, T. (2020). Disunited States of America: Responses to coronavirus shaped by hyper-partisan politics. The Guardian, May 29

Medina, J., \& Gebeloff, R. (2020). What the Coronavirus Revealed About Life in Red versus Blue States. The New York Times, May 25

Miller, D. A., Smith, E. R., \& Mackie, D. M. (2004). Effects of Intergroup contact and political predispositions on prejudice: Role of intergroup emotions. Group Processes \& Intergroup Relations, 7, 221-237

Milosh, M., Painter, M., Van Dijcke, D., \& Wright, A. L. (2020). Unmasking partisanship: How polarization influences public responses to collective risk. 2020-102. Chicago, IL

Newell, S. A., Girgis, A., Sanson-Fisher, R. W., \& Savolainen, N. J. (1999). The accuracy of self-reported health behaviors and risk factors relating to cancer and cardiovascular disease in the general population: A critical review. American Journal of Preventive Medicine, 17, 211-229

Pew Research Center. (2014). Religion in America: U.S. religious data, demographics and statistics. Religious Landscape Study. Retrieved December 14, 2020, https://www.pewforum.org/relig ious-landscape-study/

Pew Research Center. (2020). Republicans, Democrats move even further apart in coronavirus concerns. Pew Research. Retrieved August 14, 2020, https://www.pewresearch.org/politics/2020/ 06/25/republicans-democrats-move-even-further-apart-in-coron avirus-concerns/

Porterfield, C. (2020). Two-Thirds of religious Americans believe coronavirus is a message from god. Forbes. Retrieved June 25, 2020, https://www.forbes.com/sites/carlieporterfield/2020/05/15/ two-thirds-of-religious-americans-believe-coronavirus-is-a-messa ge-from-god/\#29ad3362a2ae

Pradhan, D., Biswasroy, P., Naik, P. K., Ghosh, G., \& Rath, G. (2020). A review of current interventions for COVID-19 prevention. Archives of Medical Research, 51(5), 363-374

Rogers, R. W., \& Prentice-Dunn, S. (1997). Protection Motivation Theory. Plenum.

Roozenbeek, J., Schneider, C. R., Dryhurst, S., Kerr, J., Freeman, A. L., Recchia, G., van der Bles, A. M., \& van der Linden, S. (2020). Susceptibility to misinformation about COVID-19 around the world. Royal Society Open Science, 7, 201199

Rosenstock, I. M. (1974). The health belief model and preventive health behavior. Health Education and Behavior, 2, 354-386

Rubin, G. J., Amlôt, R., Page, L., \& Wessely, S. (2009). Public perceptions, anxiety, and behaviour change in relation to the Swine Flu outbreak: Cross sectional telephone survey. BMJ (Online), 339,156

Rubin, G. J., Potts, H. W. W., \& Michie, S. (2010). The impact of communications about Swine Flu (Influenza A HINIv) on public responses to the outbreak: Results from 36 national telephone surveys in the UK. Health Technology Assessment, 14, 183-266

Schoch-Spana, M. (2017). Partnering with communities to foster trust, save more lives, and prompt recovery in epidemics and disasters. Health Security, 15, 22-24

Supady, A., Randall Curtis, J., Abrams, D., Lorusso, R., Bein, T., Boldt, J., Brown, C. E., Duerschmied, D., Metaxa, V., \& Brodie, D. (2021). Allocating scarce intensive care resources during the 
COVID-19 pandemic: Practical challenges to theoretical frameworks. The Lancet Respiratory Medicine, 9, 430-434

Taylor, D. B. (2020). For Black Men, Fear That Masks to Protect from Covid-19 Will Invite Racial Profiling. The New York Times. Retrieved August 13, 2020, https://www.nytimes.com/2020/04/14/ us/coronavirus-masks-racism-african-americans.html

U.S. Census Bureau. (2019a). QuickFacts: United States. Retrieved December 14, 2020, https://www.census.gov/quickfacts/fact/table/ us/pst045219

U.S. Census Bureau. (2019b). QuickFacts: United States.

USA Facts. n.d. Coronavirus Outbreak Stats \& Data. Retrieved June 25, 2020. https://usafacts.org/issues/coronavirus/

Velan, B., Kaplan, G., Ziv, A., Boyko, V., \& Lerner-Geva, L. (2011). Major motives in non-acceptance of A/H1N1 Flu vaccination: The weight of rational assessment. Vaccine, 29, 1173-1179

White, A. I. R. (2020). Historical linkages: Epidemic threat, economic risk, and xenophobia. The Lancet, 395, 1250-1251
WHO. (2020). Coronavirus disease: Advice for public. Retrieved June 25, 2020, https://www.who.int/emergencies/diseases/novel-coron avirus-2019/advice-for-public

World Health Organization. (2020). Estimating Mortality from COVID19. Retrieved March 18, 2021, https://www.who.int/news-room/ commentaries/detail/estimating-mortality-from-covid-19

Zhang, L., Tao, Y., Shen, M., Fairley, C. K., \& Guo, Y. (2020). Can Self-imposed prevention measures mitigate the COVID-19 epidemic? PLOS Medicine, 17, e1003240

Publisher's Note Springer Nature remains neutral with regard to jurisdictional claims in published maps and institutional affiliations. 